\title{
GRANADA EN LOS ATLAS NÁUTICOS DE AL-ŠARAFĪ, E IDENTIFICACIÓN DE UN MODELO MALLORQUÍN PARA LA CARTA DE AL-MURSİ
}

\author{
GRANADA IN AL-SHARAFI'S NAUTICAL ATLASES, \\ AND IDENTIFICATION OF A MAJORCAN MODEL \\ FOR AL-MURSII'S CHART
}

\begin{abstract}
La identificación de Granada con el icono del fruto del granado en los atlas náuticos de al-Šarafī $(1551,1571)$ alimenta una imagen evocadora del reino nazarí, a la vez que solidaria con los exiliados moriscos en el contexto de la defensa turco-otomana del Islam en el Mediterráneo. Tanto la imagen de Granada como de la Sierra de Segura en la cartografía náutica mediterránea plantea interesantes cuestiones de tipo conceptual y estilístico pero, sobre todo, documenta la interacción entre las tradiciones magrebí-andalusí y mallorquina. La carta de al-Mursī (1461) se presenta aquí como testimonio de ello.

Palabras clave: Cartografía náutica magrebí y andalusí; Al-Šarafí; Granada; Fruto del granado; Moriscos; Segura; Guadalquivir; Al-Mursī; Jaume Bertrán; Berenguer Ripoll.
\end{abstract}

\author{
MónICA HerRera CASAIS \\ Universidad de Barcelona
}

The identification of Granada with the icon of a pomegranate in al-Sharafi's nautical atlases $(1551,1571)$ fuels an evocative image of the Nașrid Kingdom, which also implies support to morisco refugees in the context of the Ottoman Turkish defence of Islam across the Mediterranean. The depiction of Granada and Sierra de Segura in Mediterranean chartmaking raises interesting questions of conceptualization and design but, above all, provides evidence to the interaction between the Maghrebi-Andalusian and Majorcan traditions. Al-Mursî's chart (1461) is presented here as a testimony for this.

Keywords: Maghrebi and Andalusian chartmaking; Al-Sharafī; Granada; Pomegranate; Moriscos; Segura; Guadalquivir; Al-Mursī; Jaume Bertrán; Berenguer Ripoll.

\section{Introducción $^{1}$}

Las miniaturas de ciudades, castillos y monumentos, entre muchas otras, como las de fauna o barcos, que se dibujan en la cartografía

${ }^{1}$ Las conclusiones se enmarcan en el proyecto de investigación Cartografía náutica árabe en el contexto mediterráneo (ca. 1300-1600): Influencias entre oriente y occidente, de la Universidad de Barcelona (Ministerio de Educación y Ciencia HUM200503375/FILO). Deseo expresar mi agradecimiento a la Prof. Mercè Comes por su definitivo impulso a la redacción de este estudio. 
náutica de lujo que aquí se estudia son recursos visuales con una doble función ornamental e informativa. En este contexto, la iconografía es un lenguaje de signos equivalente a la semiótica moderna. Este trabajo aborda la identificación de Granada y, por extensión, de al-Andalus, con el icono del fruto del granado en los atlas náuticos del cartógrafo tunecino 'Alī al-Šarafí. Ello obliga a repasar la simbología de este fruto en el Islam y su asociación histórica con la ciudad de Granada. Además, la vinculación de la granada de al-Šarafī con la hidrografía del Guadalquivir y del Segura plantea interesantes cuestiones sobre la funcionalidad de estos ríos como frontera gráfica de los territorios del Islam peninsular. La imagen de su nacimiento en la Sierra de Segura, primero en los mapas de al-Idrīsī, y después en las cartas náuticas mediterráneas, es un magnífico ejemplo de transmisión de conocimientos geográficos, así como de interacción entre las tradiciones árabe (magrebí y andalusí) y mallorquina de cartografía. En el curso de la investigación se ha identificado la fuente mallorquina de la carta de al-Mursī.

\section{La imagen de Granada en los atlas de al-Šarafī}

Un elemento distintivo de la cartografía de la familia al-Šarafĩ de Sfax (Túnez) es la miniatura de una granada colocada en el interior de la Península Ibérica como símbolo del antiguo reino nazarí de Granada. Con ella se alimenta una imagen evocadora y nostálgica de al-Andalus, en el contexto de las migraciones forzosas de moriscos de la Península Ibérica y la defensa turco-otomana del Islam en el Mediterráneo del siglo XVI. La granada es recurrente en toda la producción conservada del taller familiar que se compone de dos atlas náuticos $(1551,1571)$ y una carta náutica mapamundi (1579) de 'Alī al-Šarafî, más una versión de esta última de su hijo Muhammad al-Šarafī $(1600-01)^{2}$. No se conserva nada de la cartografía anterior del abuelo

${ }^{2}$ Herrera Casais, M., Cartografía náutica árabe en el siglo XVI: Los atlas de 'Alī al-Šarafì de Sfax, tesis doctoral en preparación; idem, "The Nautical Atlases of "Alī al-Sharafi”", Suhayl, 8 (2008), 223-63 (con referencia a la granada en p. 254); idem, "Sacred Geography in Two $16^{\text {th }}$-Century Tunisian Nautical Atlases", en preparación; Nallino, C.A., "Un mappamondo arabo disegnato nel 1579 da 'Alī ibn Ahmad ash-Sharafĩ di Sfax", Raccolta di scritti editi e inediti, Roma, 1944, V, 533-48. Al-Šarafī se cita en Sezgin, F., Mathematische Geographie und Kartographie im Islam und ihr Fortleben im Abendland: Autoren, Frankfurt am Main, 2007, 430-31.

Al-Qanțara (AQ) XXX 1, enero-junio 2009, pp. 221-235 ISSN 0211-3589 
(Muḥammad) ni del padre (Aḥmad), cuya datación, hacia la primera mitad del siglo XVI, sería más próxima a la fecha de la caída de Granada (1492). No obstante, el propio 'Alī al-Šarafī afirma que su carta mapamundi estaba copiada de un prototipo del abuelo, que a su vez se había basado en un modelo mallorquín, entre otras fuentes como al-Idrīsī ${ }^{3}$.

En los atlas de 'Alī al-Šarafī la granada aparece en la carta seccional que incluye casi toda la Península Ibérica (excepto una sección del Levante y Cataluña), además de Marruecos. En el primero (1551), la fruta es verde, con el corazón y cáliz rojos, mientras que en el segundo (1571), el corazón se compone de tres capas en azul, rojo y blanco. La granada lleva la leyenda Ŷabal al-Talŷ bi-l-Andalus (Sierra Nevada en al-Andalus) ${ }^{4}$, aunque ésta se sitúa ligeramente hacia el sureste del macizo ibérico central y alcanza el nacimiento del Guadalquivir y el Segura. La leyenda para Sierra Nevada está escrita en tinta negra en el primer atlas y roja en el segundo. Curiosamente, no se añaden otros topónimos ni para el origen de los ríos, en lo que correspondería a la Sierra de Segura, ni para la propia Granada. El curso de los ríos se dibuja únicamente en el segundo atlas en el que brotan del cáliz de la fruta. En este último, la hidrografía del Guadalquivir y el Segura delimita un territorio algo más amplio que el de las fronteras del reino de Granada, que abarcaba desde las serranías de Ronda y Málaga hasta los confines de Almería con Murcia. El Guadalquivir desagua correctamente en el golfo de Cádiz (junto al topónimo Qādis*), mientras que el Segura lo hace entre los topónimos para Alicante (al-Qant* / Alaqant*) y el cap d'Alcodra o cabo de Huertas (qāb Larkūdrā), que en la realidad quedan al norte de la desembocadura ${ }^{5}$.

${ }^{3}$ Cf. Nallino, "Un mappamondo", 538; y comentario de Herrera, "The Nautical Atlases", 227-30.

${ }^{4}$ El topónimo al-Andalus designa a la Península Ibérica como entidad geográfica, independientemente del grado de expansión territorial de los dominios cristianos o musulmanes: García Sanjuán, A., "El significado geográfico del topónimo al-Andalus en las fuentes árabes", Anuario de Estudios Medievales, 33, 1 (2003), 3-36. Sobre la toponimia árabe para Sierra Nevada: al-Idrīsī, Description de l'Afrique et de l'Espagne, R. Dozy y M.J. de Goeje (ed. y trad.), Leiden, 1866, 203 (ed.); Torres Palomo, M.P.P., "Sierra Nevada en los escritores árabes", MEAH, 16-17 (1967-68), 57-88.

5 En estudios sobre cartografía náutica, el asterisco (*) distingue los topónimos escritos en tinta roja para las principales ciudades y puertos, así como los accidentes prominentes de la costa. El nombre del cap d'Alcodra, de origen árabe, está ampliamente docu- 
El icono de la granada es un elemento de influencia andalusí en 'Alī al-Šarafĩ aunque no está claro que su introducción en la cartografía del taller familiar fuese una idea original suya. Es posible que ésta ya apareciera en el prototipo de carta mapamundi del abuelo, del que la producción conservada de los al-Šarafī es parcialmente dependiente. La granada también podría proceder de otro atlas, hoy perdido, de Abū 1-'Abbās Ahmad al-Andalusī, un cartógrafo poco conocido establecido en Estambul que, por su cronología, podría tratarse de un morisco o descendiente de moriscos ${ }^{6}$. 'Alī al-Šarafĩ cita este último atlas como fuente del suyo de 1571, sin aportar más detalles. El símbolo de la granada es infrecuente en la cartografía náutica mallorquina, pero está documentado en una carta de 1489 de Jaume Bertrán ${ }^{7}$. En ella, un caballero cristiano, quizá el propio rey Fernando el Católico, sujeta en su mano una granada como símbolo de poder. Esta figura se sitúa junto a Sierra Nevada que aparece cubierta por las armas de Castilla y Aragón, en alusión a la inminente caída del reino nazarí en poder de los Reyes Católicos. Aparentemente, la cartografía de tradición mallorquina ya circulaba en Túnez hacia principios del siglo $\mathrm{XV}^{8}$, pero es imposible determinar si el modelo mallorquín del abuelo de 'Alī al-Šarafĩ contenía miniaturas similares a las de la carta de Bertrán.

Parece más probable que 'Alī al-Šarafī o su abuelo se familiarizaran con el icono de la granada por influencia de los moriscos refugiados en Túnez que mantuvieron viva la cultura andalusí ${ }^{9}$. Desde el si-

mentado en las cartas náuticas de Mallorca desde principios del siglo XIV: Pujades i Bataller, R.J., "La toponímia litoral del País Valencià en la cartografia portolana medieval", en Congrés internacional de toponímia i onomàstica catalanes (Valencia, 2001), Valencia, 2002, (357-74) 368-69. Además, la toponimia litoral de Valencia y Cataluña en la cartografía mallorquina y veneciana está extractada en idem, Les cartes portolanes. La representació medieval d'una mar solcada, Barcelona, 2007, 386ss.

${ }^{6}$ Lo estudia Herrera, "The Nautical Atlases", 233-35.

${ }^{7}$ La describe Sáenz-López, S., Imagen y conocimiento del mundo en la edad media a través de la cartografía hispana, tesis doctoral presentada en la Universidad Complutense, Madrid, 2007, I, 631-32. También se recoge en idem, "La Reconquista cartográfica. El Islam peninsular en la cartografía medieval hispana", Treballs de la Societat Catalana de Geografia, 61-62 (2006), (279-301) 295-96, fig. 11.

8 Esta cuestión se discute en Herrera, "The Nautical Atlases", 232-33. Algunos ejemplos de influencia mallorquina y, sobre todo, veneciana en al-Ṭanŷî, un cartógrafo que aparece en Túnez por esas fechas, se estudian en idem, "The 1413-14 Sea Chart of Ahmad al-Ṭanji”, en E. Calvo et al. (eds.), A Shared Legacy: Islamic Science East and West, Barcelona, 2008, 283-307.

9 Sobre la implantación morisca en Túnez, particularmente tras la gran expulsión de 1609-14, y la política de acogida de la regencia otomana: Epalza, M. de, Los moriscos

Al-Qanțara (AQ) XXX 1, enero-junio 2009, pp. 221-235 ISSN 0211-3589 
glo XIII, muchos andalusíes ejercieron un destacado papel en las ciencias, artes y arquitectura del gobierno hafșí (1228-1574) y la posterior regencia otomana. Aunque las migraciones masivas de moriscos a Túnez disminuyeron en el siglo XVI, especialmente durante la etapa de injerencia española (1573-74), sus descendientes fomentaron la memoria de la Granada islámica ${ }^{10} \mathrm{y}$, seguramente, propagaron su identificación con el fruto del granado.

\section{El icono del fruto del granado y su asociación con la ciudad de Granada}

La granada es símbolo de fertilidad y abundancia en las culturas de Oriente Medio ${ }^{11}$. Se cita en la Biblia, como elemento ornamental del Templo de Salomón y poético del Cantar de los Cantares, así como en el Corán, como objeto de la creación y fruta del jardín del Paraíso ${ }^{12}$. Es un atributo de soberanía persa sasánida que se transmite a la decoración de la arquitectura de la Siria omeya. Varios ejemplos pueden observarse en los complejos palaciegos de 'Anŷar y Qușayr 'Amra, de la época del califa al-Walīd b. 'Abd al-Malik (gob. 705-15) ${ }^{13}$, además de los mosaicos de la mezquita Omeya de Damas-

antes y después de la expulsión, Madrid, 1992, 261-76; idem, "Sidi Bulgayz, protector de los moriscos exiliados en Túnez (s. XVII). Nuevos documentos traducidos y estudiados", Sharq al-Andalus, 16-17 (1999-2000), 141-72; Bernabé Pons, L.F.: "Notas sobre la cohesión de la comunidad morisca más allá de su expulsión de España", Al-Qanțara, 29, 2 (2008), 307-32.

${ }^{10}$ Un ejemplo curioso es un testimonio de 1640 que alimenta esta memoria con la literatura española del Siglo de Oro: Tratado de los dos caminos por un morisco refugiado en Túnez: MS S2 de la Colección Gayangos, Biblioteca de la Real Academia de la Historia. Ed. de A. Galmés de Fuentes, con estudio de L. López-Baralt, Madrid-Oviedo, 2005. Lo cita Bernabé Pons, L.F., "La nostalgia granadina de los moriscos", en J.A. González Alcantud y A. Malpica Cuello (eds.), Pensar la Alhambra, Barcelona-Granada, 2001, (165-81) 180-81.

${ }_{11}$ Muthmann, F., Der Granatapfel: Symbol des Lebens in der alten Welt, Friburgo, 1982.

12 La Biblia. Versión electrónica de La Santa Sede (Ciudad del Vaticano, 2008 en curso de publicación), I Reyes 7:42; II Crónicas 3:16, 4:13; Cantar de los Cantares 4:3, 4:13, 6:7, 6:11; 7:13; 8:2; y El Corán, J. Cortés (trad.), Barcelona, 1992, 6:99, 6:141, 55:68.

13 Finster, B., "Vine Ornament and Pomegranates as Palace Decoration in "Anjar", en B. O'Kane (ed.), The Iconography of Islamic Art: Studies in Honour of Robert Hillenbrand, Edimburgo, 2005, 143-58; Almagro, M. et al., Qusayr 'Amra: Residencia y baños omeyas en el desierto de Jordania, Granada, [2002], 60, 61, 120, figs. 32, 33. 
co y la Qubbat al-Ṣajra de Jerusalén ${ }^{14}$. La bibliografía sobre al-Andalus omeya documenta su uso igualmente en Madīnat al-Zahrā' y la mezquita de Córdoba ${ }^{15}$. En casi todos los casos, la granada aparece vinculada al Árbol de la Vida del Paraíso con el que se asocia desde antiguo ${ }^{16}$, aunque es un motivo menos frecuente que las hojas de vid y acanto. En Córdoba, se importaron granados de Siria para plantarse expresamente en los jardines de al-Rușāfa, la residencia de campo del emir 'Abd al-Raḥmān I (gob. 756-88) ${ }^{17}$. A este acontecimiento aluden unos versos de Ibn Faraŷ al-Ŷayyānī (m. 976) ${ }^{18}$. En las huertas del Generalife, también se cultivaron granados para la corte nazarí. Las propiedades de sus frutos son bien conocidas en la farmacología islámica medieval.

El nombre de la ciudad de Granada es anterior a la conquista árabe de la Península Ibérica. En lengua mozárabe, el vocablo designa el fruto del granado (sing. granāta; distinto del col. ár. rummān), como consta en el Botánico Anónimo Sevillano (siglos XI-XII) ${ }^{19}$, y ya era corriente en la lengua romance peninsular antes del año 1000. Explican su significado Yāqūt (1179-1229) y al-Maqqarī (1577-1632) ${ }^{20}$. Según Pocklington (1988), en los siglos IX-X el topónimo evolucionó

${ }^{14}$ Creswell, K.A.C., Early Muslim Architecture. Part One: Umayyads A.D. 622-750 [With a Contribution on the Mosaics of the Dome of the Rock in Jerusalem and of the Great Mosque in Damascus by M. Gautier-van Berchem (pp. 213-372)], Oxford, 1969, proporciona numerosos ejemplos (esp. pp. 268, 269); idem, Early Muslim Architecture. Part Two, Oxford, 1940, 133 para la mezquita de al-Aqșà en Jerusalén; Flood, F.B., The Great Mosque of Damascus: Studies on the Making of an Umayyad Visual Culture, Leiden, 2001, passim (índice p. 329).

15 Pavón Maldonado, B., El arte hispano-musulmán en su decoración floral, Madrid, 1990, tablas VII (esp. p. 45) y XXVI; sobre todo n. ${ }^{\circ}$ XXVI-99:547.

${ }^{16}$ Representa la esperanza en la vida eterna: Lechler, G., "The Tree of Life in Indo-European and Islamic Cultures", Ars Islamica, 4 (1937), 369-420.

17 Al-Maqqarī, Naf̣h al-țîb min guṣn al-Andalus, R. Dozy et al. (eds.), Leiden, 1855, I, 123, 305. Recoge la noticia Samsó, J., Las ciencias de los antiguos en al-Andalus, Madrid, 1992, 20-22. Sobre la finca: Marín, M., "al-Ruṣāfa (4. In Muslim Spain)", $E I^{2}, 8$, (1995).

18 Pérès, H., Esplendor de al-Andalus. La poesía andaluza en árabe clásico en el siglo XI, M. García-Arenal (trad.), Madrid, 1983, 195 (n. ${ }^{\circ} 80$ ); sobre la granada en poesía andalusí: 186, 193, 194, 195.

19 Asín Palacios, M., Glosario de voces romances registradas por un botánico anónimo hispano-musulmán (siglos XI-XII), Madrid-Granada, 1943, n. ${ }^{\circ} 265$. Además, vid. Corriente, F., Dictionary of Andalusi Arabic, Leiden, 1997, 218-19.

20 Al-Maqqarī, Naf̣h al-țīb, I, 93; Yāqūt, Mu' yyam al-buldān, F. Wüstenfeld (ed.), Leipzig, 1868, III, 788; los cita Pocklington, R., "La etimología del topónimo 'Granada'”, Al-Qanțara, 9, 2 (1988), (375-402) 388.

Al-Qanțara (AQ) XXX 1, enero-junio 2009, pp. 221-235 ISSN 0211-3589 
hacia «rojo/a como una granada», dando lugar a la arabización poética al-Hamrā' (la Roja) para los palacios de la Alhambra ${ }^{21}$.

La identificación iconográfica de Granada con la fruta del mismo nombre es anterior a 1492 como testimonia la carta de Bertrán (1489) antes mencionada. Tras la caída de los nazaríes, el escudo de armas de los Reyes Católicos incorporó precisamente una granada. Este elemento quedó también reservado para el escudo de la ciudad, así como para el de la familia morisca Granada Benegas descendiente del sultán Yūsuf IV b. al-Mawl (gob. 1431-32), entronizado por Juan II de Castilla (gob. 1406-54) ${ }^{22}$. Su heráldica, en la que aparecen cinco granadas junto al lema de la dinastía nazarí (gāliba), puede verse en el Generalife y en la capilla de San Pedro de la Iglesia del Sagrario de Granada ${ }^{23}$. En los siglos XVI-XVII, miniaturas con granadas adornan libros impresos en la ciudad o relacionados con su historia. Entre ellos, el Vocabulista arauigo en letra castellana de Pedro de Alcalá (Granada, 1505) ${ }^{24}$ y las crónicas de Francisco Bermúdez de Pedraza: Antigüedad y excelencias de Granada (Madrid, 1608) e Historia eclesiástica (Granada, 1638) ${ }^{25}$. El primer plano profesional de la ciudad, la célebre Plataforma de Granada (1610) del arquitecto Ambrosio de Vico, lleva igualmente granadas en la cartela de leyendas ${ }^{26}$. De especial significación

21 Pocklington, "La etimología", 375-402. De forma complementaria, vid. Abellán Pérez, J., 'La sucesión nazarí, el topónimo 'Granada' y el origen de su población, según un cronista del siglo XVII”, Sharq al-Andalus, 10-11 (1993-94), (197-209) 204-5.

22 Seco de Lucena, L., "Alamines y Venegas, cortesanos de los nasríes", MEAH, 10, 1 (1961), 127-42; Soria Mesa, E., "Una versión genealógica del ansia integradora de la élite morisca. El origen de la Casa de Granada”, Sharq al-Andalus, 12 (1995), 213-21.

23 Moreno Olmedo, M. ${ }^{a}$ A., Heráldica y genealogía granadinas, Granada, 1989, 88-91, lám. IX-2. Describe el escudo en p. 88: «partido; $1 .^{\circ}$ : en campo azur cinco granadas de oro; $2^{\circ}$ : en azur tres fajas de plata; entrando en punta, una bandera roja; escudo en abismo o escusón, con las armas de los reyes nazaríes; campo de plata y banda negra. En jefe, una cinta, con la leyenda "Servire Deo regnare est"».

24 Alcalá, P. de, Vocabulista arauigo en letra castellana, Granada, 1505, fols. 270r-270v. Facsímile electrónico de la Biblioteca Virtual Miguel de Cervantes, Alicante, 2003.

25 Bermúdez de Pedraza, F., Antigüedad y excelencias de Granada, Madrid, 1608, facsímile a cargo del Colegio Oficial de Arquitectos de Andalucía Oriental, Granada, 1981; discute las leyendas relativas al nombre y armas de Granada en libro II, caps. 16-20, 22; idem, Historia eclesiástica, Granada, 1638, facsímile con prólogo de I. Henares Cuéllar, Granada, 1989.

26 Una copia de 1612-14, estampada por el grabador flamenco Francisco Heylan, se conserva en el Archivo Histórico Municipal de Granada: Gómez-Moreno, J.M., El arquitecto granadino Ambrosio de Vico, Granada, 1992, 149, 153-58, fig. 32; Henares Cuéllar, I. y López Guzmán, R. (coords.), Antigüedad y excelencias, Catálogo de exposición en el 
es la Alegoría del río Darro de Granada (ca. 1676-80) de Pedro Atanasio Bocanegra. En esta pintura barroca, el Darro es un joven efebo que exhibe un cetro rematado por una granada ${ }^{27}$.

\section{El nacimiento del Guadalquivir y el Segura en la geografía árabe medieval}

Las fuentes árabes localizan el nacimiento del Guadalquivir y el Segura en la llamada Sierra de Segura (Ŷabal Šaqūra) que abarca el conjunto de las Sierras de Cazorla, Segura y Las Villas de la actual provincia de Jaén. En el Nuzhat al-muštāq de al-Idrīsī (comp. Palermo, 1154), una de las principales fuentes de la familia al-Šarafí, ésta se incluye en la primera sección del cuarto clima que comprende casi toda la Península Ibérica. Según sus noticias:

Segura es una ciudadela habitada, bellamente construida y situada en la cima de una impresionante e inexpugnable montaña. De su base nacen dos ríos, uno de ellos es el de Córdoba, llamado río grande, y el otro es el río blanco que discurre por Murcia. El primero nace en un lago en que confluyen las aguas de la montaña, después se sumerge, sale a la superficie y continúa su curso hacia occidente (...) El segundo brota de la montaña y luego se dirige hacia el sur (...) Se dice que tienen el mismo nacimiento ${ }^{28}$.

En la cartografía de al-Idrīsī, la Sierra es una cordillera roja de cuya base brotan dos ríos verdes. La fortaleza de Segura no se dibuja, pero tampoco la ciudad de Granada cuya posición se indica con una roseta de señalización ${ }^{29}$. Abū l-Fidā' (1273-1331) describe los ríos en

Museo de Bellas Artes de Sevilla, editado por la Junta de Andalucía, 2007, 142, 143 (lám.).

27 Se conserva en el Museo de Bellas Artes de Córdoba: Orozco Díaz, E., Pedro Atanasio Bocanegra, Granada, 1937. Véase la reproducción en el catálogo Antigüedad y excelencias, 140-141.

28 Al-Idrīsī, Description de l'Afrique, 195-96 (ed.). Sobre los ríos: Terés, E., Materiales para el estudio de la toponimia hispanoárabe: Nómina fluvial, Madrid, 1986, I, 143-44 (Segura), 399-402 (Guadalquivir).

${ }^{29}$ Véase el MS arabe 2221 de la Bibliothèque nationale de France, el más antiguo conservado (ca. 1300): La Géographie d'Idrīsì. Un atlas du monde au XII siècle. Facsímile electrónico a cargo de A. Vernay-Nouri, París, 2000, con ed. árabe del Istituto Universitario Orientale (Opus geographicum, Nápoles, 1970-84, 560-61), y trad. de P.A. Jaubert (Géographie d'Edrisi, París, 1840, II, 42), revisada por A. Nef y E. de la Vaissière. Además, vid. Miller, K., Mappae arabicae. Arabische Welt und Länderkarten des

Al-Qanțara (AQ) XXX 1, enero-junio 2009, pp. 221-235 ISSN 0211-3589 
la sección de hidrografía terrestre de la introducción al Taqwim al-buldān ${ }^{30}$. En ella, el nacimiento del Guadalquivir se sitúa en $38 ; 40^{\circ} \mathrm{N} 15^{\circ} \mathrm{O}$ (unos $12^{\circ}$ al oeste de la realidad), según las coordenadas que copia para la propia Sierra del Kitāb bast al-ard fì l-tūl wa-l- 'ard de Ibn Sa'īd al-Magribī (m. 1286) ${ }^{31}$. Al-Zuhrī de Granada (s. XII) es más explícito al diferenciar el nacimiento de los ríos ${ }^{32}$ que, de hecho, se hallan en márgenes opuestos de la Sierra: el del Guadalquivir en Cazorla y el del Segura en la Sierra de Segura. En su cabecera, el primero se alimenta de una red de numerosos arroyos, lo que explica la dificultad histórica para identificar su origen exacto. $\mathrm{Su}$ curso pasa por Córdoba y Sevilla y desemboca en el Atlántico en Sanlúcar de Barrameda. La cuenca alta del Segura recorre una zona de escarpada orografía, el curso medio pasa por Murcia y Orihuela y finalmente desagua en el Mediterráneo en Guardamar del Segura. La historiografía árabe menciona con frecuencia la fortaleza de Segura. En ella se refugia Ibn 'Ammār (1031-86), visir de al-Mu'tamid de Sevilla (gob. 1069-90), tras declararse en rebeldía ${ }^{33}$.

\section{Notas comparativas con la cartografía náutica de Mallorca y el Mediterráneo islámico, e identificación de una de las fuentes de la carta de al-Mursī}

Con frecuencia, en la cartografía náutica de tradición mallorquina se dibuja el cauce completo o parcial de ríos importantes, como son el Ebro, el Tajo o el Guadalquivir en la Península Ibérica. De hecho, el

9-13 Jahrhunderts, Stuttgart, 1926, I; idem, Weltkarte des Arabers Idrisi vom Jahre 1154, Stuttgart, 1928.

${ }^{30}$ Reinaud, J.-T. y Slane, M.G. de (eds.), Géographie d'Aboulféda, París, 1840, 47-48; y trad. J.-T. Reinaud, 1848, II:1, 58-59; y castillo de Segura en p. 252 (p. 176 ed.).

${ }^{31}$ Kennedy, E.S. y Kennedy, M.H., Geographical Coordinates of Localities from Islamic Sources, Frankfurt am Main, 1987 (2. ${ }^{\mathrm{a}}$ ed. revisada y ampliada por M. Comes, en preparación): s.v. Shaqura Mountains (SAA).

32 Al-Zuhrī, Kitāb al-Dja 'rāfiyya, M. Hadj-Sadok (ed.), Bulletin d'Etudes Orientales, 21 (1968), 209. Sus noticias del paso del Segura por el cañón de los Almadenes (pp. 208-7) se recogen en Vallvé Bermejo, J., "La división territorial en la España musulmana (II): La cora de Tudmīr (Murcia)", Al-Andalus, 37, 1 (1972), 166-67.

33 Idem, "La división territorial en la España musulmana: La cora de Jaén", Al-Andalus, 34, 1 (1969), 76 (para la Sierra de Cazorla, p. 64). Al final del período almorávide, también es ocupada por un vasallo de Ibn Mardanīš, gobernador de Valencia y Murcia: Lévi-Provençal, E., "Shakūra”, $E I^{2}, 9$, (1997). 
Guadalquivir es el principal eje fluvial de Andalucía, con un destacado papel histórico y económico en toda la Edad Media y hasta mucho después del descubrimiento europeo de América. Los cartógrafos mallorquines, muchos de origen judío, representan el Guadalquivir y el Segura con un nacimiento común en la Sierra de Segura que concuerda con la concepción geográfica de al-Idrīsī, aunque su estilística está más elaborada. En la versión mallorquina, el monte de Segura, con uno o dos picos, suele estar coronado por un castillo que, a veces, sustituye a la montaña. De su base brotan los ríos cuyo curso hasta las desembocaduras delimita un triángulo que sirve de frontera gráfica entre territorios de cristianos y musulmanes ${ }^{34}$. Es igualmente representativa la imagen del castillo de Granada que, en la cartografía de Angelino Dulcert (fl. 1330-45), el taller de los Cresques (incluido el Atlas Catalán, ca. 1375) y Macià de Viladesters (fl. 1384-1423) ${ }^{35}$, despliega un estandarte rojo con una imitación de la gāliba nazarí ${ }^{36}$. El entorno verde de Sierra Nevada adquiere mayor entidad que el castillo de Granada a partir de la carta de 1439 de Gabriel de Vallseca. Más tarde, Granada se identifica con un musulmán sentado sobre Sierra Nevada en otra carta de Jaume Bertrán de $1482{ }^{37}$. Las alusiones a la Granada islámica desaparecen de la cartografía mallorquina inmediatamente después de 1492, e incluso la carta arriba mencionada de Bertrán (1489) anticipa su final.

34 Rey Pastor, J. y García Camarero, E., La cartografía mallorquina, Madrid, 1960, 29; Sáenz, Imagen y conocimiento, 369.

35 Sáenz, Imagen y conocimiento, 446-47. Véase el ejemplo de L'Atles Català 1375. El món i els dies, facsímile con estudios de G. Llompart i Moragues, R.J. Pujades i Bataller y J. Samsó Moya, Barcelona, 2005, fol. III.

36 Esta gāliba se describe en el armorial portulano del Libro del conosçimiento (finales s. XIV), que recoge buena parte de la vexilología mallorquina: Libro del conosçimiento de todos los rregnos et tierras et señorios que son por el mundo, et de las señales et armas que han, facsímile del Manuscrito Z, con transcripción y estudio de M. ${ }^{\mathrm{a} J}$. Lacarra, M. ${ }^{\mathrm{a} C}$. Lacarra Ducay y A. Montaner, Zaragoza, 1999, escudo n. ${ }^{\circ}$ XXII (p. 160): «Et las senalles deste rreyñado son vn pendon vermejo con letras de oro aravjgas commo las traya Mahomat su propheta» (Descripción heráldica, p. 28: “de gules, una inscripción pseudo-cúfica de oro puesta en faja”). Además, vid. Sáenz, Imagen y conocimiento, 630-32; Martínez Enamorado, V., "Lema de príncipes. Sobre la gāliba y algunas evidencias epigráficas de su uso fuera del ámbito nazarí", Al-Qanțara, 27, 2 (2006), 537-38 (cita el Atlas Catalán en p. 537-38).

37 Véase la reproducción de la carta completa en Kamal, Y., Monumenta cartographica Africae et Aegypti, El Cairo, 1951, V:1, 1503; y el detalle de la Península Ibérica en Sáenz, "La Reconquista", 295, fig. 10. Además, debe destacarse que en ella se añadieron anotaciones en turco-otomano, principalmente en el norte de África, el Levante mediterráneo y el Egeo, que documentan su uso en un contexto islámico.

Al-Qanțara (AQ) XXX 1, enero-junio 2009, pp. 221-235 ISSN 0211-3589 
La Sierra de Segura como nacimiento de los ríos Guadalquivir y Segura se dibuja también en dos cartas del Mediterráneo islámico. La primera es la de Ibrāhīm al-Ṭabīb al-Mursī, un médico cartógrafo de origen andalusí, de quien se conserva una carta firmada en Trípoli (de Berbería o Levante) en $1461{ }^{38}$. Esta presenta numerosos elementos de influencia mallorquina, como son las viñetas del castillo de Segura, la ciudad de Barcelona (con la distintiva torre de señales de Montjuïc) ${ }^{39}$ y las islas Canarias orientales, que son casi idénticas a las de la carta que Jaume Bertrán y Berenguer Ripoll confeccionan en Barcelona en $1456{ }^{40}$. Ello indica que al-Mursī copiaba, entre otros, de un modelo casi contemporáneo del taller de alguno de estos dos cartógrafos. Esta es la primera vez que se identifica la fuente mallorquina de una carta árabe. Pujades (2007) atribuye la ornamentación a Ripoll, ya que ésta es muy diferente de las otras dos cartas firmadas solamente por Bertrán (Mallorca, 1482 y 1489). Las demás viñetas urbanas de al-Mursī, como las de El Cairo, Génova y Venecia, sugieren la consulta de otras fuentes cartográficas ${ }^{41}$. Además, es significativo que al-Mursī omita precisamente la miniatura de Bertrán y Ripoll para Santiago de Compostela.

38 Comes Maymó, M., "Ibrāhīm al-Ṭabīb al-Mursī”, en Las artes y las ciencias en el Occidente musulmán. Sabios mursies en las cortes mediterráneas, Murcia, 2007, 74-81; y los comentarios de Herrera, "The Nautical Atlases", 231, 232; Sezgin, Mathematische Geographie: Historische Darstellung, II, 32-33.

39 Sobre la viñeta de Barcelona: Rosselló i Verger, V.M., Portolans procedents de col-leccions espanyoles. Segles XV-XVII, Barcelona, 1995, 29-30; Cebrián, J.L., "Gènova, Barcelona i València en les cartes portolanes dels segles XIV i XV", Mètode, 53 (2007), 82-87.

40 Aparentemente, no se conserva ninguna otra carta de Ripoll. La que firma conjuntamente con Bertrán se incluye en Pujades, Les cartes portolanes, C58, 261.

${ }^{41}$ De especial interés es su miniatura de la Ka 'ba circunscrita en un círculo: Herrera, "Sacred Geography". Esta parece vinculada con la tradición de los esquemas de geografía sagrada islámica para determinar la dirección de la alquibla. Sobre este tipo de esquemas: King, D.A. y Lorch, R.: "Qibla Charts, Qibla Maps, and Related Instruments", en J.B. Brian y D. Woodward (eds.), The History of Cartography: Cartography in the Traditional Islamic and South Asian Societies, Chicago-Londres, 1992, II:1, 189-205. La $\mathrm{Ka}$ 'ba de al-Mursī también enlaza con la imagen del santuario en las certificaciones de lujo de la peregrinación a La Meca: un ejemplo de 1432 está en Ettinghausen, R., "Hilāl (ii. In Islamic Art)", $E I^{2}, 3$, (1971), fig. 15. En el Atlas Catalán (ca. 1375) y el Mapamundi Catalán de la Biblioteca Estense de Módena (ca. 1450-60), tanto La Meca como Medina se representan de forma convencional (en al-Mursī, Medina es igual al castillo de Segura), con leyendas que distorsionan el valor de estos lugares sagrados para el Islam: Sáenz, Imagen y conocimiento, 479-94, 729; además de L'Atles Català, I, 62 y II, fol. V.

Al-Qanțara (AQ) XXX 1, enero-junio 2009, pp. 221-235 ISSN 0211-3589 
Siguiendo el modelo mallorquín, al-Mursī dibuja el castillo de Segura (con la etiqueta Šaqūra), rodeado por una muralla, en sustitución de la Sierra de Segura ${ }^{42}$. Los ríos Guadalquivir y Segura nacen directamente de la muralla. El primero desemboca junto al topónimo para Sevilla (Išbīliya*) y el segundo entre Alicante (Laqant*) y Guardamar. Este último topónimo se lee Gūdamār*, quizá también por influencia mallorquina, y al contrario de la Carta Magrebí anónima (ca. 1350), en la que se mantiene el topónimo al-Mudawwar (antiguo Almodóvar) que registra al-Idrīisī ${ }^{43}$. El curso de los ríos encierra un espacio para el reino de Granada, cuyos límites se extienden hasta Gibraltar (Ŷabal al-Fath) y Vera (Bīra* / Bayra*), en poder de los reyes nazaríes hasta 1462 y 1488 respectivamente. El territorio lleva la etiqueta: Yazìrat al-Andalus - harasa-hā Allāh Ta'ālà* (Península de al-Andalus - Dios Altísimo la proteja), con igual invocación religiosa que El Cairo. La ciudad de Granada no se representa. En la carta de Bertrán y Ripoll, el espacio de Granada está coloreado en verde, posiblemente en alusión a Sierra Nevada.

En el Mediterráneo islámico, la carta de Hāâŷy Abū 1-Ḥasan, que reúne elementos de la cartografía náutica otomana, árabe y mallorquina, incluye viñetas de la Sierra de Segura y Granada. La bibliografía la sitúa en Estambul en la época de Sulaymān el Magnífico (gob. 1520-66), coincidiendo con la máxima expansión del imperio otomano ${ }^{44}$. En ella se dibuja el monte de Segura (sin el castillo), de cuya base nacen el Guadalquivir y el Segura con dobles líneas onduladas en azul y verde. Debajo, Granada aparece como una fortaleza dorada y blanca emplazada sobre un montículo verde. En su etiqueta todavía se lee wilāyat Garnāta, es decir, regencia de Granada, según la terminología administrativa de las provincias del imperio otomano ${ }^{45}$. Esta viñeta es muy diferente de los múltiples castillos que adornan la

42 Al-Mursī repite el diseño del castillo en otros enclaves como la ciudad santa de Medina (véase la nota anterior) y las ciudades del Danubio. Un diseño similar reaparece en la carta anónima (ca. 1500-50) conservada en la Seo de Barcelona: Rosselló, Portolans, n. $^{\circ} 9$.

${ }^{43}$ La toponimia de la Carta Magrebí está publicada por Vernet, J., "The Maghreb Chart in the Biblioteca Ambrosiana", Imago Mundi, 16 (1962), n. ${ }^{\circ}$ 145. Algunos comentarios sobre la misma están en Herrera, "The Nautical Atlases", 250, 252. Sobre el topónimo Guardamar en la cartografía náutica mallorquina y veneciana: Pujades, "La toponímia litoral", 370-71; idem, Les cartes portolanes, 386ss.

${ }^{44}$ Sezgin, Mathematische Geographie: Historische Darstellung, II, 33-34.

45 Sobre el término wilāya, de origen árabe: İnalcik, H., "Eyālet", $E I^{2}, 2$, (1965).

Al-Qanțara (AQ) XXX 1, enero-junio 2009, pp. 221-235 ISSN 0211-3589 
carta y, a primera vista, parece un desarrollo de la imagen verde de Sierra Nevada en la carta de 1449 de Pere Rossell ${ }^{46}$.

\section{Conclusiones}

El icono del fruto del granado como símbolo del reino nazarí de Granada es un elemento distintivo de influencia andalusí en los atlas náuticos del cartógrafo tunecino 'Alī al-Šarafĩ. Con él se alimenta una imagen evocadora y nostálgica de al-Andalus no sólo en Túnez, destino de numerosos exiliados moriscos, sino entre una posible clientela turco-otomana implicada en la defensa moral del Islam en el Mediterráneo del siglo XVI. Más allá de su función ornamental, este icono debe interpretarse como una declaración política en favor de la Granada islámica. Con él, al-Šarafĩ expresa dos realidades geográficas relacionadas como son los dominios del antiguo reino nazarí y el nacimiento de los ríos Guadalquivir y Segura, cuyo curso hasta las desembocaduras sirve de frontera gráfica entre cristianos y musulmanes. En las cartas náuticas de tradición mallorquina, la representación del origen de los ríos en la Sierra de Segura, podría estar basada en la Geografía de al-Idrīsī, aunque luego experimenta su propia evolución estilística y conceptual. La interpretación mallorquina influye directamente en el trabajo de Ibrāhīm al-Mursī en Trípoli (de Levante o Berberia) y el de Haŷŷy Abū 1-Ḥasan, quizá en Estambul. El primero refleja las fronteras granadinas con fidelidad histórica y maneja una fuente mallorquina contemporánea.

46 Pujades, Les cartes portolanes, C48. Además, Winter, H., "Petrus Roselli", Imago Mundi, 9 (1952), (1-11) 2, 4 destaca el detalle de Sierra Nevada tanto en cartas de Batista Beccari (1426) como de Pere Rossell (fl. 1447-68).

Al-Qanțara (AQ) XXX 1, enero-junio 2009, pp. 221-235 ISSN 0211-3589 
'Alī al-Šarafī, atlas náutico 1571. Oxford, Bodleian Library: MS Marsh 294 (fol. 7r).

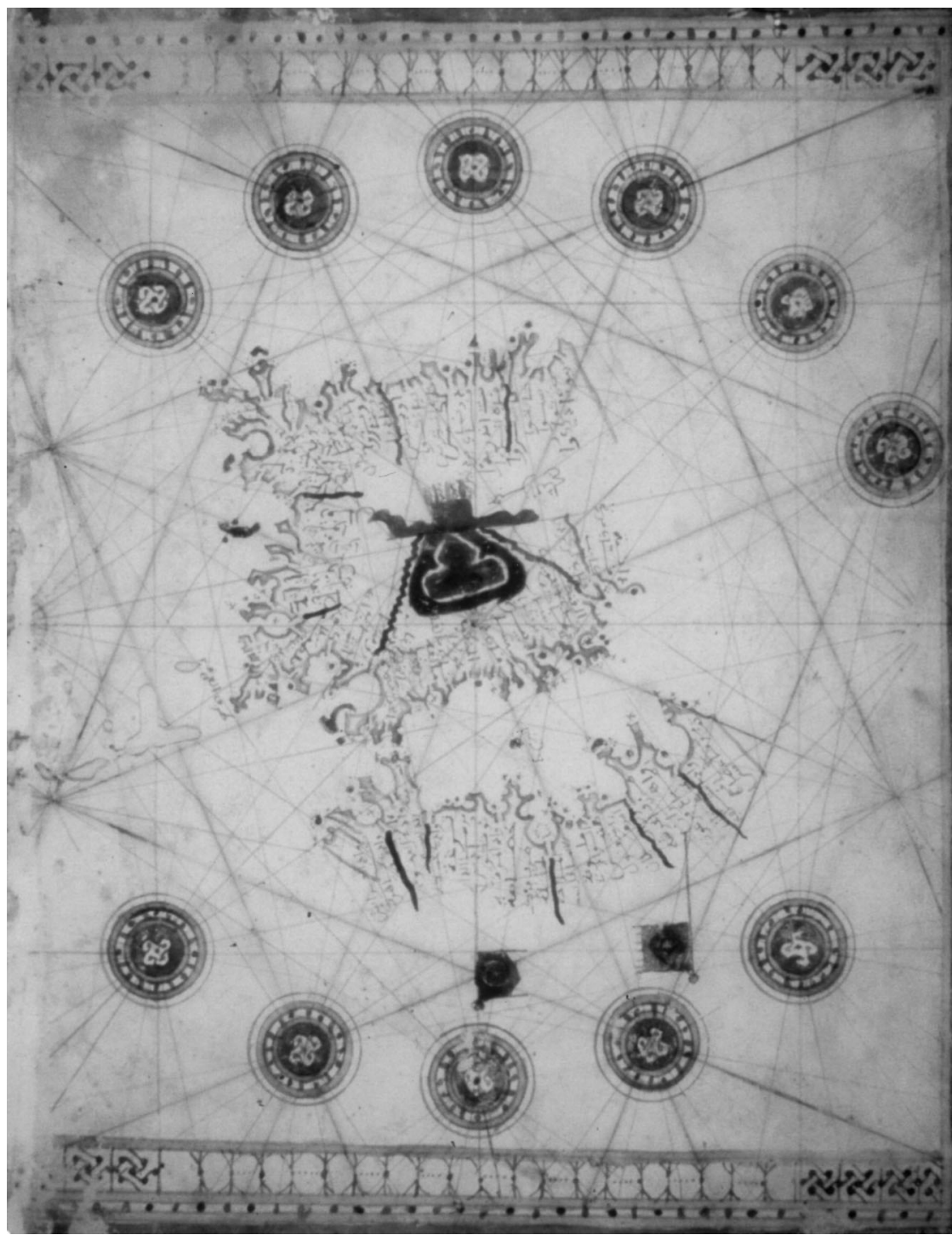


Ibrāhīm al-Mursī, carta náutica 1461: detalle de la Península Ibérica. Estambul, Museo Naval (Deniz Müzesi): n. ${ }^{\circ} 882$.

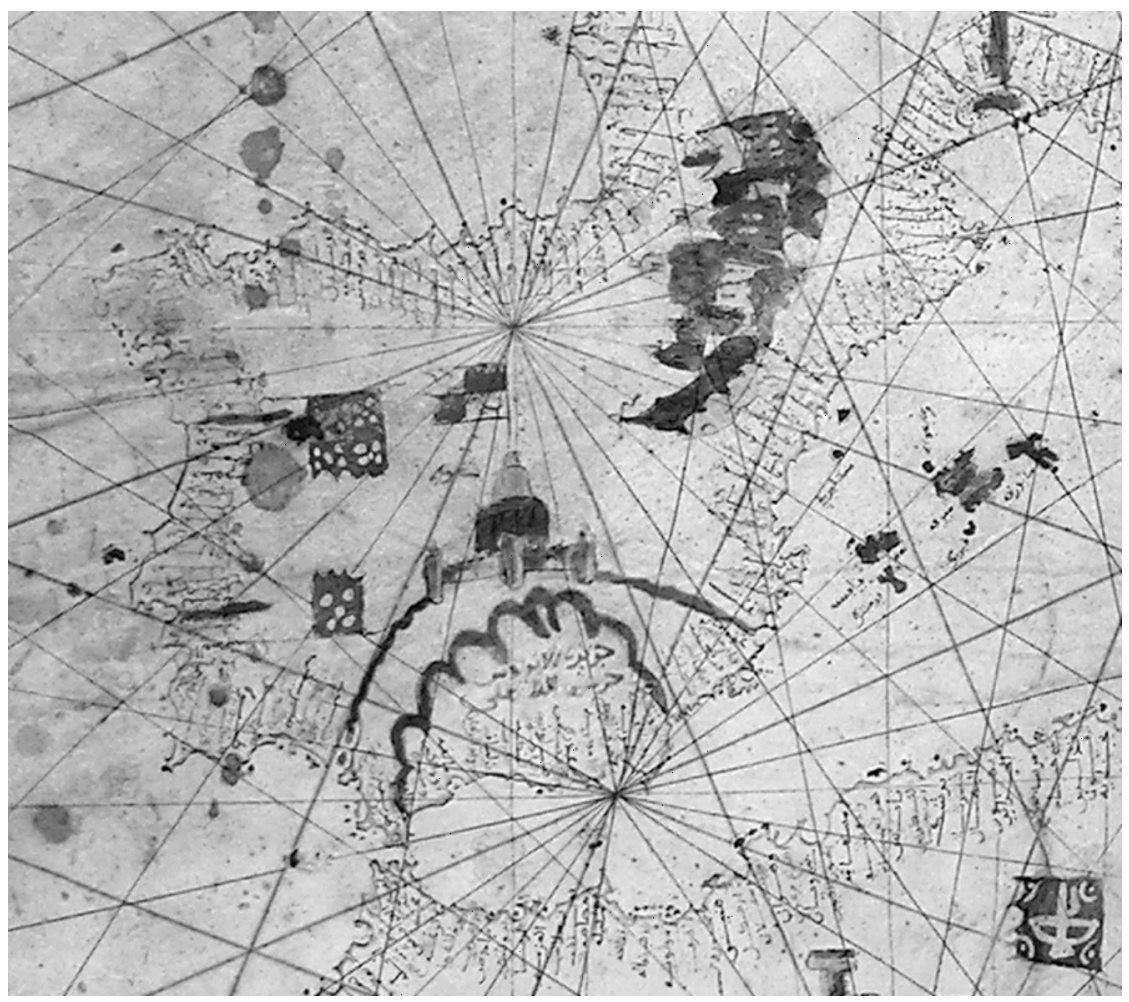

Recibido: $26 / 06 / 2008$

Aceptado: 19/12/2008 